Vol. 1, No. 1, Juli 2017, 46-55

Available Online at https://ejournal.warmadewa.ac.id/index.php/kulturistik DOI: http://dx.doi.org/10.22225/kulturistik.1.1.216

\title{
OFFENSIVE LANGUAGES IN BAD BOYS 2
}

\author{
I Made Astu Mahayana \\ Warmadewa University \\ astumahayana@yahoo.co.id
}

\begin{abstract}
This research focuses on the forms of offensive language and the functions in social context found in Bad Boys 2 movie. The writer applied some methods, such as data source, data collection, and data analysis. The data source of this research was Bad Boys 2 movie's script. The movie is chosen because there are many expressions consisting of offensive language. The library research technique was used in collecting the data by quoting the sentences that support the topic of discussion. In analyzing the data, the writer applied the offensive language theory proposed by Timothy Jay (1992) in his book entitled Cursing in America and the theory of speech function proposed by Janet Holmes (1992) in his book entitled An Introduction to Sociolinguistics as the main theory. The analysis in this paper was also supported by other references which are related to this topic. The result of this research shows that there are only eight forms found in the data source. They are cursing, profanity, taboo, obscenity, vulgarity, slang, epithets, insult and slur.
\end{abstract}

Keywords: offensive languages, communication, forms, social function

\section{INTRODUCTION}

As a social creature, people cannot stand alone without making contact. People need communication among them when they are going to make a contact. Communication is important people's daily life. People need communication to express their mind, transfer information and convey the message, ideas, and emotion. In daily interactions, people use language to communicate with others. Language is all the words and sentences used to express our thoughts (Hill, 1958: 1) Language will be performed in a form such as dialogue or conversation.

Dialogue or conversation occurs in a spoken language or written language. Especially in spoken language, it is used to express emotions directly. People will be easier to understand the spoken language because it is able to determine the meaning of language through the words that are spoken by the speaker that is expressed with a gesture, facial expression, and intonation. For example, when people are in a bad mood or angry they will speak with strong words or they will swear with the bright red face. Meanwhile, if they are in a good mood or happy, they will speak nicely with a smile but to express sadness, they will speak in a weak voice and sad facial expression.

There are two elements in the conversation; they are people (speaker and listener) and message. The people in this context are the people who are involved in the conversation and the message is the content of the conversation. To exchange message, they need language as a toll of conversation. Therefore, it can be said that a language is a medium of communication.

Many languages have words which are considered dangerous, holly or shocking and which are only used in certain situations or by certain people. For 
example, the 'god' and 'hell' are not considered shocking when they are used with literal meaning but they are considered shocking if they are used for swearing. Swearing is not necessarily impolite, inasmuch as offensive language is often used within the boundaries of what is considered situationally appropriate in discourse; further, some instances of swearing are neither polite nor impolite (Jay \& Janschewitz, 2008). Offensive phrases could mocks or insult somebody or a group of people (attacks such as aggression against some culture, subgroup of the society, race or ideology in a tirade) (Rasavi, 2010). They will be offensive language if we use them for swearing or mocking other people.

Offensive languages are used to express the strong emotion as anger, dissatisfaction, and shocked feeling. They generally involve something society deems sacred (religion, family) or something considered taboo or prohibited or are used to insult someone personally (Sinambela, 2010)Some people used offensive language but, they did not know what they said is offensive language. Thus, this study discusses offensive language in terms of form related to social function.

Much of the increase in profanity has been attributed to the mass media, with 'Music, films, and television (Sapolsky \& Kaye, 2005). Offensive languages or profanity are social phenomena because they can be (commonly) seen in daily activity, especially movies. There are many action movies such as Mission Impossible, Die Hard, Rambo, etc. containing offensive languages. In these movies, there are so many offensive languages like 'fuck' and 'shit'. In some situations, these words are unacceptable but in others, they are appropriate things to say.

The movie is like an interpretation of human life, where actors and actresses act like people in their daily life. They tried to make perfect imitations of what people do and how people react to some kind of situations including their way to talk, move, etc. As mentioned above that offensive language is often used in movies. Actors do not only use offensive languages to express the sadness, but also to express the happiness. So it is pretty hard to identify or determine which kind of offensive languages that appropriate and inappropriate to say or which one is expressing bad or good things and which one needs a good or bad response from the listener when uttered by the speaker. That is why offensive languages become interesting to be studied and one of important aspects in language. In written works like novels or magazines the writers used the words very carefully in their works. They didn't try to use offensive languages or they changed it into other words. In the movie script, the writers use offensive languages if it is necessary. They do not change the words and they use it directly. Based on this situation, the writer is interested in analyzing offensive languages in terms of forms and the functions in social context.

\section{METHOD}

This study focuses on offensive languages in terms of forms and the functions related to social function in the Bad Boys 2 movie. The movie was chosen because the movie is a reflection of human life and in the movie, it can be seen the use of offensive languages by the actors directly. The movie script is also used in this study because movie script is a written text or work, especially for a film or television program. Screenplays or movie script can be original works or adaptations from existing works and in each movie has a movie script that makes it easier in analyzing or translating into another language. 
All data used in this paper were taken from Bad Boys 2 movie script. The writer prefers this movie as the data source because there are so many expressions in this movie consisting of offensive languages. In collecting data, firstly the movie was watched and compared with the script. After that, the offensive languages that occur in the movie were collected by watching the movie carefully and then paused it if there are any offensive languages occur, writing them in the note and marking them according to their forms. After collecting the offensive language, all data were classified based on its forms. Finally, they were analyzed descriptively based on the theories to find out their forms and the social functions. In presenting the data, the writer used the informal method. There are some theories which are suitable to the topic of discussion. The first one is the offensive language theory which is proposed by Timothy Jay (Jay, 1992) in his book entitled Cursing in America and the theory of speech function which is proposed by Janet Holmes (Holmes, 1996) in his book entitled An Introduction to Sociolinguistics.

\section{DISCUSSION}

Many languages have words or phrases which are considered dangerous, holy, magic or shocking and which are only used in certain situations or by certain people. Offensive languages are a unique phenomenon. It is unique because it is disallowed to use them in daily conversation.

Offensive languages are social phenomena because they can be (commonly) seen in daily activity and always grow up since it was found until now. They are usually uttered upon frustration, anger, dissatisfaction and other bad feelings with strong emotion included in them. Now, offensive languages are usually used to express whatever people fell, like when they are talking with someone in the same age. Sometimes, offensive languages are shocking. They are common in situations where people want to express powerful emotions by using strong language. This is called "cursing" or "swearing". When people curse or swear, sometimes the meaning of offensive languages or tabooed words can be completely changed if they compound into phrases. For example, the words fuck off and piss off have nothing to do with sex or urine. They are simply violently rude ways of saying "go away"

In Bad Boys 2 movie, there are some offensive languages used for supporting the storyline and giving emotional impact to the people who watch this movie. The explanations of offensive languages found in Bad Boys 2 movie can be analyzed according to their classification based on the forms and the functions in social context.

\section{The Forms of Offensive Language}

The first step in analyzing offensive languages in Bad Boys 2 movie is to identify all the forms of offensive languages found in Bad Boys 2 movie. Offensive languages can be classified into 10 categories based on Timothy Jay's classification, they are cursing, profanity, blasphemy, taboo, obscenity, vulgarity, slang, epithets, insult and slur, and scatology (Cressman et.al., 2009). The forms of offensive languages that occur in Bad Boys 2 movie scripts are presented below:

Cursing is intended to invoke harm of another person using certain words or phrases. It is rude or offensive words or phrase used to express violate anger. 
Cursing is also known as words or phrases spoken with the aim of punishing, injuring or destroying something or somebody. Some words or phrases which are included cursing in this movie script such as:

1. Mike : A bullet in the head'll really mess up your extensions.

Haitian Man : Take your bullet and eat that shit, man.

2. Johnny Tapia : Just fly the drugs in and ship the money out.

Now American security's so goddamned tight over the water.... and in the goddamned sky... that the rats eat my money before I can get it to Cuba.

From the data (1), the cursing is uttered by male character (Haitian man) directed to Mike, he launched the utterance 'eat that shit' in order to express his violent anger and dissatisfaction upon the situation because Mike is going to shoot him. The conversation happened when Mike is going to arrest the Haitian Man and he refuses it.

The data (2) is using the curse word 'goddamned'. The speaker (Johnny Tapia) uses this word to intensify his dissatisfaction and emotion upon the situation. He feels very angry with the security or police who always try to arrest his drugs which are delivered from shipment or airplane cargo.

Profanity is based on a religious distinction. To be profane means to be secular or behaving out. To be profane means to be ignorant of the words in a religious belief. This seeks not to denigrate God, religion or holly affairs but would be based on ignorance or indifference to these matters. Some words or phrases which are included profanity in this movie such as:
3. Captain
Mike
: The DEA? Without consulting me?!
Captain
: That's a DEA car right there.
Marcus
: Christ! Fuck!
: Cap. No. Remember your pressure points.
4. Mike
Marcus
: You all right?
: No, I'm not all right, Mike.
Three days of this shit. Got my nerves all rattled.
My ass still hurts...
Lady
...from what you did to it the other night.

The data (3) can be classified as profanity because the word 'Christ' contains religious belief. The word Christ uttered by the Captain is an expression of frustration. He says it out loud and with a burst of anger because somebody is disturbing him and makes an unpleasant situation upon him.

In data (4), the lady launched 'Oh, my Lord!' to express his feeling about bad situation. Mike and Marcus are having impolite conversation in front of the lady and her children so she expresses her feeling by saying Oh, My Lord! It shows that the lady does not believe for what she just heard.

Taboo is cultural or religious custom that forbids people to do, touch, use or talk about a certain thing, in a general agreement not to discuss or to do something. A taboo operates to suppress or inhibit certain behavior, thought or speech. The function of taboo is to prohibit the behavior of a speaker and preserve social 
cohesion. Some taboo words found in this movie such as:

5. Office Man : Got something.

Mike : What you got, dick head?

Office Man : The computer matches half tones, gray tones, densities.

Sort of like a visual code-breaking.

6. Alexei : You kill me and you will have a shit-storm.

Johnny Tapia : Should I screw your young wife.

..or visit your son, the soccer player?

Alexei : You're gonna regret this.

The word dick in data (5) is pointed sexual which means a man's penis. This word is categorized as a taboo word. Mike uses the word dick to call the office man. He does that because he has a good relationship with the office man so it is become usual to say it.

Different with data (5) the word screw in data (6) is referring to sexual in nature, in this case is to have sex. In this movie, Johnny Tapia is using the word screw to say that he will have sex with Alexei's young wife.

Obscenity has function to protect listeners from harmful language. In American English, obscene words are considered the most offensive and rarely used in public places and they are pointedly sexual in nature. The followings are some obscenity words found in the movie:

7. Haitian Man 1 : You're in my house!

This is all your fault!

Mike : You're in my country, though.

Haitian Man 1 : Fuck you, how's that?

I'm gonna kill you, motherfucker!

8. Captain : The DEA? Without consulting me?!

Mike

Captain

: That's a DEA car right there.

Marcus

: Christ! Fuck!

: Cap. No. Remember your pressure points.

The utterance motherfucker in data (7) is a word that is launched as obscene word in order to offend someone. In this conversation, the Haitian Man is very angry with Mike because he attacks and shoots the Haitian Man. So he offends and tries to humiliate Mike.

Meanwhile in data (8), the captain is screaming the word fuck to show his anger. The utterance fuck is categorized obscenity because it is brief but forceful burst of emotional language. It is more powerful in presentation in term of loudness, duration and also used to offend somebody.

Vulgarity means the language of the common person, "the person in the street" or the unsophisticated, un-socialized or under-educated persons. Vulgarism is not necessarily obscene or taboo. They just reflect the crudeness of street language. A person with vulgar manner is a person who is lacking on good taste, not refined and likely to offend many people. Some words or phrases which are included vulgarity found in this movie are: 
9. Police : You guys okay?

Mike : Yeah, we're fine.

Marcus : What you mean, "we"?

Motherfucker shot me in the ass, man.

Mike : Who shot you in the ass?

Marcus : Who? That "who" would be you.

10. Mike : That was a flip!

Marcus : That motherfucker flipped!

Mike : That one puckered up my butthole.

Marcus : Almost fucking crushed my head.

The data (9) is a conversation between Mike and Marcus. It is classified as vulgarity, because they use the vulgar word ass, as well as they are talking as close friends. In this case, the word ass is a common word in their community. Therefore, they launch this impolite word freely.

Similar with data (9), data (10) is also a close friend conversation between Mike and Marcus. Mike uses the vulgar phrase butthole to express his surprised feeling about what just happened. They are having a car chase with bad people when suddenly a car flips above their running car.

Slang is known as a vocabulary that developed in certain sub group such as teenagers, soldiers, drug users or athletes for ease of communication. It is very informal words and expressions and more common in spoken language. It is sometimes restricted to one particular group of people.

11. Marcus : Mike, you go to therapy to get your issues worked out... ...not bang your therapist.

Mike $\quad$ : See, now you just talking nasty.

12. Marcus : These drones, they're explorers of the rat world, you know. They just looking for rat pussy.

Roberto : Are you fucking with me?

The word bang in data (11) means 'to have sex'. Bang literally means a noise coming out from an explosion. But in this sentence, Marcus uses the slang word to express 'seduce the therapist'. Mike understands, and he tells Marcus that what he has been saying is nasty or it is a dirty word. They use it as a common word because they are in the same group or level in social life.

The word pussy in data (12) ordinarily refers to a 'cat'. This word refers to a female's sexual organ. In this context, this word refers to 'a hot woman' or 'a hot girl'.

Epithets are kind of offensive language used upon frustration as when someone gets something bad happened to him/her. Epithets are brief but forceful burst of emotional language. They sometimes are accompanied by loudness of tone. Based on the data analysis, epithets can be seen as the following data:

13. Police 1 : Heads up. Here comes the drop.

Police 2 : Fuck. My lens is flaring. I can't see shit. 
14. Carlos : Roberto, fucking follow them!

Roberto : I'm on it! I'm on it!

Carlos : Shit!

DEA Agent : Son of a bitch!

In the data (13), the word fuck is uttered by a male character (police 2) upon frustration because his lens is flaring and he cannot see anything. There is a little bit anger and disappointment in his tone.

Similar to data (13), data (14) is showing that the male character (DEA Agent) is really angry and upset because of the situation. This conversation happens in the car where his friend (undercover police) is attacked by some people. He utters son of a bitch! with a powerful tone to express his frustration.

Verbal attacks on other people are identified as insult and slur. They are spoken to harm other people by the word itself. Insult is intended to hurt the feeling or dignity of somebody. Meanwhile, slur may be racial, ethnic or social which denote the physical, mental or psychological qualities of the target. Some words that contain insults and slurs found in this movie are:
15. Woman : Sorry, Johnny.
Johnny Tapia : Fucking bitches.
16. Alexei : I'm sorry, I gotta hang up.
Some fucking punk thinks he can die in my club.
Ecstasy fucks them up.

As can be seen above, that Johnny uttered the word bitches in data (15) to insult the women. They are doing mistake by using his gun recklessly, so he becomes angry and launched that word. It is a rude way of saying 'whore' or a woman who has bad habit in dating or has sex with many men. It uses to harm the feeling of the woman.

Data (16) is showing the word punk that is launched by Alexei. The word punk means a worthless male person (Hughes, $2006: 370$ ). In this context of conversation, Alexei is insulting a man. He uses punk to humiliate him.

\section{The Functions of Offensive Language}

Discussing offensive language is related to communication occurred in daily life because offensive languages are often found in the conversation. People use offensive language in order to express their emotion, anger, dissatisfaction and sometimes it is intended to offend others. Jay (Cressman et.al., 2009) typifies swearing as 'a coping mechanism, a way of reducing stress' and a form of anger management. Based on this situation, we can conclude that there is a tight relation between offensive languages and communication in social life. From sociolinguistics point of view, there are some functions of language which can be used to determine the functions of offensive languages.

Jacobson (1960 in Nodoushan, 2014) distinguishes six functions of language. They are expressive function, directive function, referential function, metalinguistic function, poetic function and phatic function. Some functions which are found in the data source as the following:

Expressive function is used to express the speaker's feeling and it doesn't 
need any response from the listener. The use of this function can be seen in the examples below:

1. Mike

: And the only way that you can get to this box...

...is you got to be motherfucking Jacques

Cousteau.

We cool?

Oh, shit.

We gotta go.

Ladies : In front of my babies you got porno and homo shows up in here?

What kind of freak-ass store is this?

2. Police 1 : Heads up. Here comes the drop.

Police 2 : Fuck. My lens is flaring.

I can't see shit.

Data (1) shows that Mike uses utterance Oh, Shit. to express his emotion. These words are uttered upon frustration because his private conversation is accidentally got caught by the camera. This utterance is categorized as expressive function because it doesn't need any respond from the listener.

The word fuck in data (2) refers to a burst of emotional feeling based on anger uttered by the male character (Police 2). He is angry because his equipment doesn't work. He uses fuck to show his violent anger or to emphasize his emotion upon the situation.

The directive function is a function which orders someone to do something. It also can be defined as a command for the listener. The data can be seen below:

3. Marcus : Mike, look. Calm down.

Mike : Calm down? I'm calm.

I'm calm! Hey! Whoa! Whoa!

I am way too unstable for that bullshit.

Stop all the goddamned movement!

Everybody stop moving!

4. Mike : Why you acting like that?

Marcus : Hey Mike, go on about your business, man.

Mike : Wait no, we gonna talk about this.

Marcus : No. Get the fuck out of my face.

In the data (3), Mike uses goddamned to intensify his meaning sense that 'everybody must stop moving'. He utters an order Stop all the goddamned movement! with high tone to show his powerful emotion. Therefore, it is classified as directive function.

Meanwhile, the sentence Get the fuck out of my face in data (4) means 'go away'. Marcus shows his anger by adding the word fuck to his sentence. Fuck in this sentence shows the increasing emotion of the speaker (Marcus). The sentence will be lack of emotion if he doesn't add it.

Referential function consists of information of an action or activity. This function just provides the information without taking any respond from the listener. The use of this function can be seen in the following examples: 
Vol. 1, No. 1, Juli 2017, 54

Available Online at https://ejournal.warmadewa.ac.id/index.php/kulturistik DOI: http://dx.doi.org/10.22225/kulturistik.1.1.216

5. Carlos : Boss, it ended up crazy.

This black chica working for the Russians was a goddamned maniac lunatic.

Roberto : She saved your money.

She wasted some Haitians and got the load to the back of drop.

6. Marcus : He can't tell us shit, Mike.

He's all fucked up.

Mike : What's your point?

Marcus : Dead suspects can't say shit.

The italic sentence in data (5) is information said by Carlos to his boss, Johnny. As it can be seen above, it is just information without needing to take any respond. Carlos inserts the word goddamned which belongs to cursing. It is used to intensify his meaning sense in the sentence that the black chica is a very crazy person.

The word shit in data (6) shows that there is an anger emotion in his sentence. It is used to replace 'something' or 'anything'. The italic sentence meaning sense can be 'dead suspects cannot say something/anything'. Marcus uses it because he wants to express his emotion although it is just regular information for Mike.

In this function, a respond from the listener is a must. It expresses solidarity and empathy with others and generally used to show the relationship between the participants. The examples of this function in the movie such as:

7. Mike : What's so sad?

Marcus : Your untreated control issues.

It's not your fault.

Mike : What in the hell is that supposed to mean?

Marcus : Your mama probably refused you her tit when you were a baby.

8. Marcus : Who the fuck are you?

Reggie : Hi, Mr. Burnett. I'm Reggie.

Data (7) shows that Mike wants a respond by saying what in the hell is that supposed to mean?. He says it with a powerful emotion. It can be seen that the word 'the hell' is added in the sentence. In this sentence, he uses hell to show their relationship or claim that they are on the same social level. The normal sentence would be 'what is that supposed to mean?'

The italic sentence in the data (8) would normally be 'who are you?'. But in this sentence, Marcus inserts the word fuck to intensify his intention and he really needs a respond from Reggie. He utters it with a burst of anger because he doesn't know Reggie before and Reggie is going to take his daughter out on the first date but Marcus doesn't like it. 


\section{CONCLUSION}

Based on the result of this research, it is found that there are some points that can be concluded according to the topic of discussions. The data are showing the expressions of offensive languages based on anger, emotion, and disappointment. The result of this research shows that from ten forms of offensive language, only eight forms that are found in the data source. They are cursing, profanity, taboo, obscenity, vulgarity, slang, epithets, insult and slur. The two other forms of offensive language; blasphemy and scatology are not found because the movie is not related to any abuse of religion and human waste system.

From the social context, there are only four functions which are found in the data source such as expressive function, directive function, referential function and phatic function. Metalinguistic and poetic functions are not found. Metalinguistic is an utterance that comments on language itself. In the data source, there is no sentence contains offensive language can serve it. Poetic function is used for an aesthetic reason. This function focuses on the aesthetic feature of language, for example a poem or an ear-catching motto. Offensive languages in the data source are not related to any aesthetic feature so there is no sentence of offensive language occurs in the movie that can refer the use of language like in the poem or ear-catching motto. Mostly functions of offensive languages in this paper are used to express the feeling of the character.

\section{REFERENCES}

Cressman et.al. (2009). Swearing in the cinema: an analysis of profanity in US teen-oriented movies. Journal of Children and Media, 117-135.

Hill, A. A. (1958). Introduction to linguistics structures. USA: Harcourt Brace Jovanovich, Inc.

Holmes, J. (1996). An introduction to sociolinguistics. London and New York: Longman Group Limited.

Hughes, G. (2006). An encyclopedia of swearing. New York: M.E. Sharpe, Inc.

Jay, T. (1992). Cursing in A merica. Philadelphia: John Benjamins B.V.

Jay, T., \& Janschewitz. (2008). The pragmatics of swearing. Journal of Politeness Research, 4, 267-288.

Nodoushan, M. A. S. (2014). Speech acts or language micro- and macro-games? International Journal of Language Studies, 8, 4, 1-28.

Rasavi, A. H. (2010). Offensive language detection using multi-level classification. In Proceedings of the 23rd Canadian Conference on Artificial Intelligence (pp. 16-27).

Sapolsky, B. S., \& Kaye, B. K. (2005). The use of offensive language by men and women in prime time television entertainment. Atlantic Journal of Communication, 13, 292-303.

Sinambela, E. (2010). A study of translating vulgarism by using euphemism. Jurnal Bahasa Dan Sastra "Langue”,9, 2, 11-21. 